\title{
Research Paper: The Effect of Transcranial Direct Current Stimulation and Core Stability Training on the Balance and Disability of Patients With Multiple Sclerosis
}

\author{
Soudabeh Raeisi $^{1}$ (D, Seyed Kazem Mousavi Sadati ${ }^{\text {** }}$ (D, Mojtaba Azimian² ${ }^{2}$ \\ 1. Department of Physical Education and Sport Science, East Tehran Branch, Islamic Azad University, Tehran, Iran. \\ 2. Rofeideh Hospital, University of Social Welfare and Rehabilitation Sciences, Tehran, Iran.
}

\begin{tabular}{|l|l|l|l}
\hline $\begin{array}{l}\text { Use your device to scan } \\
\text { and read the article online }\end{array}$ & $\begin{array}{l}\text { Citation Raeisi S, Mousavi Sadati SK, Azimian M. The Effect of Transcranial Direct Current Stimulation and Core Stability } \\
\text { Training on the Balance and Disability of Patients With Multiple Sclerosis. Physical Treatments. 2021; 11(3):189-198. http:// } \\
\text { dx.doi.org/10.32598/ptj.11.3.477.1 }\end{array}$ \\
dol http://dx.doi.org/10.32598/ptj.11.3.477.1
\end{tabular}

(c) (i) (\$)

Article info:

Received: 14 Aug 2020

Accepted: 13 Feb 2021

Available Online: 01 Jul 2021

Keywords:

Transcranial Direct

Current Stimulation

(tDCS), Core training,

Multiple Sclerosis (MS),

Balance

\begin{abstract}
A B S T R A C T
Purpose: Physicians report balance disorders and fatigue as the symptoms of Multiple Sclerosis (MS) disease. The present study compares the effect of transcranial Direct Current Stimulation (tDCS) and core stability training on the balance and disability of patients with MS.

Methods: This is a pre-test, post-test experiment study. The statistical population included all patients with MS who reffered to Rofaydeh Rehabilitation Hospital in Tehran City, Iran, in the winter of 2019. A total of 30 male and female patients aged 27-70 years were selected through available and purposive sampling methods and then randomly divided into experimental and control groups (each group 15 persons). The initial measurements of the participants' kinetic variables of postural control were carried out by the posturography device, and afterward, Kurtzke Expanded Disability Status Scale (EDSS) was employed to measure disability. The participants' training included core stability training for 8 weeks (30-40 min, 3 sessions per week) with 20 min online cerebellar transcranial direct current stimulation, 2 sessions per week (The first and third sessions). Then, the research variables were measured again.
\end{abstract}

Results: The results demonstrated the significant influence of cerebellar tDCS on the variables of postural control equilibrium in the second sensory condition $(\mathrm{P}<0.001)$, third sensory condition ( $\mathrm{P}<0.001$ ), fourth sensory condition $(\mathrm{P}<0.001)$, fifth sensory condition ( $\mathrm{P}=0.034)$, and combine equilibrium $(\mathrm{P}<0.001)$. Besides, the cerebellar current stimulation enhanced the sensory performance of the experimental group in using the vestibular system input data $(\mathrm{P}<0.001)$ and vision $(\mathrm{P}<0.001)$, but it had no significant effect on the ability to use somatosensory input $(\mathrm{P}=0.203)$ and vision preference $(\mathrm{P}=0.343)$. This research also revealed that the cerebellar current stimulation decreased EDSS in MS patients $(\mathrm{P}=0.026)$.

Conclusion: The cerebellar tDCS has a beneficial effect on balance, EDSS, and modified fatigue impact scale in MS patients. The study findings also indicate that the cerebellum, vestibular system, and visual system are related, and they have an impact on balance, and cerebellar stimulation can facilitate learning motor skills.

\footnotetext{
* Corresponding Author:

Seyed Kazem Mousavi Sadati, PhD.

Address: Department of Physical Education and Sport Science, East Tehran Branch, Islamic Azad University, Tehran, Iran.

Phone: +98 (21) 33594951

E-mail:drmousavisadati@gmail.com
} 


\section{Highlights}

- tDCS improves the balance of MS patients.

- tDCS has a positive effect on the disability of MS patients.

- tDCS can facilitate the learning of motor skills.

\section{Plain Language Summary}

MS is a chronic inflammatory disease of the central nervous system that is commonly seen in young adults between the ages of 20 and 40. Physicians reported the balance disorders as one of the earliest symptoms of this disease. Decreased muscle endurance, balance, and increased physical disability are major causes of falls in MS patients. The cerebellum is one of the most common areas of the brain that plays a major role in balance and execution of movements, which is damaged by this disease. In recent years, many interventions have been made to stimulate or inhibit the activity and function of the cerebellum in the human. tDCS a simple, non-invasive, endurable, and safe method without adverse effects, is one of the interventions that researchers have considered. Some research has shown that tDCS can affect the functions of different areas of the brain. Since tDCS is considered as a cheap and cost-effective intervention, in this study, this method was used as a complementary treatment to improve cerebellar function along with core stability exercises. The results of our study showed that electrical stimulation of the cerebellum with direct current has beneficial effects on the balance and disability of MS patients and also electrical stimulation of the cerebellum can facilitate the learning of motor skills. Therefore, this method can be used as a complementary treatment in MS.

\section{Introduction}

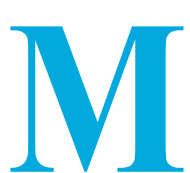

ultiple Sclerosis (MS) is a common chronic inflammatory disease of the Central Nervous System (CNS), primarily diagnosed in young adults between 20 to 40 years old. Its female-to-male ratio is 3 to 1 [1]. It may thus target the best period of a person's life, gradually debilitating with aging. The disease has become considerably significant due to its growing prevalence in recent years and its high economic burden, as its treatment costs account to approximately $2.5 \$$ billion per year in the US [2-4]. Physicians reported the balance disorders as one of the earliest symptoms of this disease [1], followed by falls, causing significant injuries to MS patients [5]. About 50\% of MS patients have experienced at least one fall, and one-third have experienced recurrent falls. Increased number of falls exposes the patients to more injuries, and the fear of falls declines the physical activities and even the daily routine of patients [6]. Increased severity of the disease (physical disability index) and decreased ability to walk are among the main reasons for falls. Also, low muscular endurance and fatigue are among the sub-factors involved in MS patients' falls [7].

The Kurtzke Expanded Disability Status Scale (EDSS) is a tool used currently to assess the disability of MS patients
[8]. It has been accepted as a standard scale for assessing the MS disease progress and has replaced other instruments due to examining patients' disability in a broader range than other methods and criteria [9]. Despite the advancement of the medical sciences in recent years, no definite treatment has been proposed for MS, and the therapeutic approaches merely reduce the symptoms or slow down the disease process [3]. Besides, the drugs have many side effects. Therefore, in recent years, patients were drawn toward non-medicinal therapies, known as complementary medicine [10] Exercise therapy is a complementary medicine [11]. Concerning function, the body's central system is responsible for transmitting the forces and torques between the upper and lower limbs during daily activities; however, MS can result in changes in endurance and the core muscle mass volume in these patients in comparison to healthy people. It also causes an imbalance in central muscles while walking. For instance, an increase in the activity of the lateral trunk muscles in the non-affected side in MS patients can be a remedial mechanism for increasing the progression of the affected side leg in the swing phase [12].

Consequently, the strength of the abdominal muscles and muscles in the lumbopelvic-hip region can be increased by training core stability $[12,13]$. The cerebellum is one of the common regions for plaque formation in this illness [14]. It is the center of coordination for maintaining body balance [15]. Many interventions 
were made to stimulate or inhibit the activity of this vital organ in recent years, such as cerebellar Transcranial Direct Current Stimulation (tDCS), which is a simple, non-invasive, endurable, and safe method without adverse effects and a tool for improving the balance. In this method, the intermembrane potential is changed, aiming to alter the excitability of neurons. Depending on whether the active electrode is anode or cathode, tDCS can increase or decrease the brain excitability [16]. Yahia et al. studied the potential role of tDCS rehabilitation on MS and showed its positive impact on reducing and probably delaying the MS progress. Many symptoms were improved and it was promised that tDCS will be used as treatment for MS patients in the future [17].

Nevertheless, current research demonstrated an inconsistency in tDCS results that prevents a clear conclusion regarding the effects of tDCS on controlling the body status. Mora et al. analyzed the effects of tDCS on various regions of brain and showed the significant impact upon stimulation of primary motor cortex (M1), which is more visible in healthy people and people with cerebral palsy. However, these effects were seen when the primary motor cortex was stimulated, and the cerebral stimulation requires more examinations [18]. Some basic clinical theories consider tDCS as an alternative treatment for pharmacotherapy and others consider it a complementary medicine that can be used with pharmacotherapy. Given that tDCS is a cheap and cost-effective intervention, it draws the attention of centers facing financial and economic problems. Therefore, paying attention and caring for MS patients seems necessary due to the rapid increase of its mortality, high cost of treatment, and various problems that MS patients face [3]. If the effectiveness of this technique is approved, it can be employed as a proper choice in developing countries [19]. Thus, the researcher sought to answer whether the core stability training plus cerebellar tDCS can improve the balance and disability index in patients with MS.

\section{Materials and Methods}

This research has a pre-test, post-test experimental design. The statistical population included all MS patients who reffered to Rofeideh Rehabilitation Hospital, Tehran City, Iran, in winter 2019. Of them, 30 male and female patients aged 27 to 70 years were selected through non-probability and purposive sampling method. The inclusion criteria were as follows: suffering from relapsing-remitting MS with disability level of 3 to 6 [20] approved in this research by the neurologist; not engaging in regular physical exercise since 2 months before the present research; attaining the score of 25 or higher in the cognitive impairment assessment questionnaire [21]; lacking the record of anesthesia in the past 6 months; not having cardiovascular disease, diabetes, arthritis, metabolic disease, or diseases such as epilepsy that increases the risk of stimulation; lacking any dermal eczema; and not being metal pieces present close to the electrodes. Afterward, based on their age and through block randomization, the participants were divided into two groups: experimental group (real current stimulation+core stability training) and control group (sham-stimulation+core stability training).

The exclusion criteria were as follows: patients' failure to regularly come to visit, a panic attack in the participant (increasing the level of disability), being scared of receiving current stimulation, or a lot of fear of posturography (Equitest) movement that results in the participants' unwillingness to cooperate effectively, diagnosis with another rare disease or disorder and side effects of receiving tDCS such as itching at electrodes site, severe burning sensations, and permanent headache. In the present research, the tDCS and TACS (transcranial alternating current stimulation) safety screening questionnaires were employed to assess the patients' general health status and investigating whether the tDCS method is safe to use.

The questionnaire was first designed by Keel et al. (2001) and completed by the research team of the University of Birmingham in 2015 [22]. The Kurtzke Expanded Disability Status Scale (EDSS) was employed to quantify the disability in eight functional body systems (brain, cerebellum, brainstem, basal ganglia, sensory, intestine, bladder, and vision). The EDSS includes 21 scores and the graded between 0 to 10 that zero signifies the normal status and 10 is death caused by MS [23], and the Mini-Mental State Exam (MMSE) was used to assess the cognitive impairment of the patients. This questionnaire was invented in 1975 by Marshal Folstein for screening dementia. The MMSE is widely used in Western countries as a tool for the diagnosis and screening of dementia [21]. Seyedian et al. (2007) researched to determine the validity of the MMSE. The results indicated that this exam has sufficient capability and reliability and is applicable in the segregation of people with dementia with a score of 22 [24].

The Sensory Organization Test (SOT), a dynamic computer positive chiropractic Equitest model made by the American company Neurocom, one of the most advanced devices for evaluating kinetic variables is used to assess balance in different sensory states and function of visual, vestibular, and somatosensory effective in controlling posture. The Equitest is a unique assessment 
tool that provides quantitative data on postural control and a suitable tool for analyzing age-related oscillation mechanisms $[25,26]$. To apply stimulation, a tDCS device, model NEUROSTIM2 (serial No. T - NS2 - 9804 - 14, manufactured by Medina Teb company), was employed. A 2-mA transcranial direct current was applied to the cerebellum by placing the $2-\mathrm{cm}$ anode electrode lower than the inion point and cathode electrode on the buccinator muscle on the right side [27].

The purpose and stages of the research and safety considerations pertinent to using tDCS were completely explained to the patients, and they were ensured that their data would be kept confidential. All information obtained will be used only for research purposes. After the participants signed the written informed letter of consent, the exercise and intervention sessions were started under the supervision of the rehabilitation specialists and physicians of Rofeideh Hospital. To carry out the research, the researcher initially collected and completed a health assessment form for each participant through an in-person interview to collect the required data for the research, especially to investigate the side effects of tDCS. Then, the patient's illness or health status was checked. The occurrence of tDCS side effects was among the exclusion criteria of the research. Besides, through a 30-point MMSE inventory, the attention and calculation, memory, language, ability to do simple commands, and the temporal and spatial orientation in the participants were examined, and the sample of MS patients were selected among the participants meeting the research inclusion criteria. Afterward, a one-day course was held to familiarize the participants with the type and manner of carrying out the exercises, then, the exercise and stimulation sessions were commenced as follows:

A) The core stability training program: 8 weeks ( 3 sessions per week, every other day), and each session lasted 40-60 min.

B) The cerebellar transcranial direct current stimulation (tDCS): 8 weeks ( 2 online sessions per week), in the first and third sessions of each week, a 20-min real stimulation in the experimental group, and 30-second sham-stimulation in the controlled group were applied. (It should be noted that none of the participants knew whether they were receiving real or placebo stimulation).

The basis of the selected exercises in this protocol was the specific spinal stabilization exercises, proprioception training of lumbopelvic region, abdominal drawing-in maneuver by contracting multifidus muscle, then, by maintaining the aforesaid stability maneuver, using the obtained dynamic stability in different positions (supine, prone, and squatting), plus adding dynamic components (limb movement and using a Swiss ball) in the subsequent stages. The exercises included three levels, proceeding from level 1 exercises to level 3 exercises. The level 1 exercises included static contractions in a stable position, level 2 exercises included dynamic movements in a stable environment, and level 3 exercises included dynamic movements in an unstable environment, and progressively, resistance exercises were carried out in this environment. A Swiss ball was used to create an unstable environment. The extra load was applied by increasing the time and repetition (sets and repetitions), enhancing the complexity of the movement, and changing the support surface concerning the participant's capabilities [20]

The data were analyzed by SPSS, version 23 . The level of significance was considered $\alpha \leq 0.05$ and $\alpha \leq 0.001$. The normal distribution of the data was investigated through the Shapiro-Wilk test. Levene's test was used for checking the equality of the intergroup variances. Box's M test was used to examine the equality of covariance of the variables in the experimental and control groups.

\section{Results}

Table 1 presents the mean and standard deviation of the anthropometric variables and Body Mass Index (BMI) of the experimental and control group. The normality of data distribution and homogeneity of variance were determined using the Shapiro-Wilk and Levene's tests. According to the results, the assumption of normality of data distribution is not rejected $(\mathrm{P}>0.05)$. Furthermore, the mutual impact of group and stage in the linear regression model was not significant. Thus, the assumption of the conformity of the slope of the regression lines was not rejected either. Considering the presumptions of analysis of covariance, this method was employed for investigating the difference between the post-test scores in the experimental groups. Table 2 presents the results of these tests. Considering that the data of the disability variable were ordinal, the Mann-Whitney U test was used to examine the intergroup difference after the post-test. Table 3 presents the results of these tests.

\section{Discussion}

This research revealed that cerebellar tDCS has a significant impact on the variables of postural control and balance. Accordingly, cerebellar tDCS improved the posture by integrating the visual and vestibular information for the assessment of the spatial body status and generating force for controlling. Most of the previous studies 
Table 1. Demographic properties of the experimental $(n=15)$ and control groups $(n=15)$

\begin{tabular}{cccc}
\hline & Groups & & Mean \pm SD \\
\cline { 3 - 4 } Variables & Age $(\mathrm{y})$ & Experimental Group & Control Group \\
\cline { 3 - 4 } & Height $(\mathrm{cm})$ & $47.40 \pm 8.28$ & $50.80 \pm 8.57$ \\
Weight $(\mathrm{kg})$ & $1.69 \pm 0.06$ & $1.73 \pm 0.12$ \\
Body Mass Index $\left(\mathrm{kg} / \mathrm{m}^{2}\right)$ & $75.40 \pm 9.73$ & $76.80 \pm 5.29$ \\
\hline
\end{tabular}

Table 2. Mean \pm SD of the study groups and a summary of intergroup comparison results using ANCOVA

\begin{tabular}{|c|c|c|c|c|c|c|}
\hline \multirow{2}{*}{ Variables } & \multirow{2}{*}{ Stages } & \multicolumn{2}{|c|}{ Mean $\pm S D$} & \multirow{2}{*}{$\begin{array}{l}\text { Intergroup F Com- } \\
\text { parison }\end{array}$} & \multirow{2}{*}{ Intergroup P } & \multirow{2}{*}{$\begin{array}{l}\text { Small Effect } \\
\text { Size (d) }\end{array}$} \\
\hline & & Control Group & Intervention Group & & & \\
\hline \multirow{3}{*}{ First sensory condition } & Pre-test & $81.87 \pm 7.16$ & $84.47 \pm 7.99$ & & & \\
\hline & & & & 0.02 & 0.867 & 0.00 \\
\hline & Post-test & $85.00 \pm 7.28$ & $87.60 \pm 8.27$ & & & \\
\hline \multirow{3}{*}{ Second sensory condition } & Pre-test & $79.60 \pm 12.02$ & $76.40 \pm 9.89$ & & & \\
\hline & & & & 18.18 & $P<0.001$ & 0.40 \\
\hline & Post-test & $81.33 \pm 11.98$ & $79.40 \pm 9.74$ & & & \\
\hline \multirow{3}{*}{ Third sensory condition } & Pre-test & $72.13 \pm 10.41$ & $74.93 \pm 10.59$ & & & \\
\hline & & & & 23.75 & $P<0.001$ & 0.46 \\
\hline & Post-test & $74.40 \pm 9.96$ & $82.20 \pm 9.19$ & & & \\
\hline \multirow{3}{*}{ Fourth sensory condition } & Pre-test & $68.53 \pm 8.74$ & $70.46 \pm 10.63$ & & & \\
\hline & & & & 37.69 & $P<0.001$ & 0.58 \\
\hline & Post-test & $70.46 \pm 8.65$ & $80.33 \pm 6.17$ & & & \\
\hline \multirow{3}{*}{ Fifth sensory condition } & Pre-test & $55.73 \pm 11.06$ & $58.33 \pm 11.29$ & & & \\
\hline & & & & 52.46 & $P<0.001$ & 0.66 \\
\hline & Post-test & $57.46 \pm 10.64$ & $64.46 \pm 11.50$ & & & \\
\hline \multirow{3}{*}{ Sixth sensory condition } & Pre-test & $43.20 \pm 13.08$ & $44.93 \pm 14.20$ & & & \\
\hline & & & & 2.24 & 0.146 & 0.077 \\
\hline & Post-test & $44.86 \pm 13.10$ & $45.80 \pm 13.96$ & & & \\
\hline \multirow{3}{*}{ Combined equilibrium } & Pre-test & $66.84 \pm 5.33$ & $68.25 \pm 6.33$ & & & \\
\hline & & & & 42.45 & $P<0.001$ & 0.611 \\
\hline & Post-test & $68.92 \pm 5.24$ & $73.64 \pm 5.47$ & & & \\
\hline \multirow{3}{*}{ Somatosensory system } & Pre-test & $0.97 \pm 0.16$ & $0.91 \pm 0.15$ & & & \\
\hline & & & & 1.70 & 0.203 & 0.05 \\
\hline & Post-test & $0.96 \pm 0.17$ & $0.91 \pm 0.15$ & & & \\
\hline \multirow{3}{*}{ Vestibular system } & Pre-test & $0.68 \pm 0.15$ & $0.69 \pm 0.12$ & & & \\
\hline & & & & 16.32 & $P<0.001$ & 0.37 \\
\hline & Post-test & $0.68 \pm 0.14$ & $0.73 \pm 0.12$ & & & \\
\hline \multirow{3}{*}{ Vision system } & Pre-test & $0.84 \pm 0.14$ & $0.83 \pm 0.13$ & & & \\
\hline & & & & 17.08 & $P<0.001$ & 0.38 \\
\hline & Post-test & $0.83 \pm 0.10$ & $0.92 \pm 0.11$ & & & \\
\hline \multirow{3}{*}{ Vision preference } & Pre-test & $0.85 \pm 0.13$ & $0.89 \pm 0.17$ & & & \\
\hline & & & & 0.93 & 0.343 & 0.03 \\
\hline & Post-test & $0.86 \pm 0.12$ & $0.90 \pm 0.15$ & & & \\
\hline
\end{tabular}


Table 3. Results of Mann-Whitney U test for disability index

\begin{tabular}{rrrr}
\hline Mean Rank of Experimental Group & Mean Rank of Control Group & Statistic Value & Z \\
\hline 179 & 286 & 59 & 2.252 \\
\hline
\end{tabular}

investigated the impact of the cerebral tDCS on motor performance and reported the positive impact of its motor behavior on the performance of motor tasks. The results of this section of the research are consistent with the findings of Piloni et al. [28] and inconsistent with the findings of Piloni et al. [29]. Piloni et al. studied the impact of a-tDCS (anode at $\mathrm{c} 3$ and cathode at Fp2) plus 10 sessions of cycling in MS patients and concluded that cerebral a-tDCS could improve the balance and gait in these patients. However, Piloni et al. examined the influence of a-tDCS (anode at c3 and cathode at Fp2) plus one session of cycling in MS patients and concluded that the cerebral a-tDCS cannot improve the balance and gate speed in these patients. However, the first (availability of sensory afferent information) and the sixth sensory conditions (providing various inputs of the visual system and proprioceptive) were not significant $(\mathrm{P}=0.1460)$.

A part of the research indicated that the cerebellar tDCS of MS patients in the experimental group was increased using the vestibular system input data and visual sensory. However, it had no significant impact on the ability to use somatosensory input and vision preference. In other words, the results demonstrated that this real cerebellar tDCS plus core stability training could improve some aspects of balance control in MS patients that depend on the postural function of the vestibular system of the inner ear. These findings indicated that cerebral stimulation could facilitate learning the balance-motor skills and motor compatibility in controlling the stature. Accordingly, the role of the cerebellum and vestibular apparatus of the inner ear and the relationship between them must be considered. Even though the cerebellum has always been a significant organ due to its major role in coordinating motor activities, new studies have been carried out to reveal other cerebellum functions.

Recently, the cerebellum has been of considerable importance on account of its role in the assessment of motor errors when walking and learning $[30,31]$. The results of this section of the research are consistent with those of Zandvliet et al., who found out that anodal cerebral stimulation of the opposite side of the damaged region in patients with chronic brain stroke has a positive impact on the functional balance [32]. Besides, the results of Portvelit et al. demonstrated that anodal (cerebral) tDCS, even without simultaneous motor training, can lead to a short-term improvement in the duration of posture compatibility and balance in healthy people [33]. However, Steiner et al. investigated the impact of anodal (cerebral) tDCS on learning a complex motor skill and obtained no positive results. They justified the result by stating that the young participants performed the motor skill to the highest learning level, preventing more progress by anodal tDCS [34].

The results of this research revealed that cerebellar tDCS could have beneficial effects on disability in MS patients. No research has been carried out regarding the impact of tDCS on the disability scale in MS patients. Therefore, there is no literature in this regard. However, concerning the impact of physical exercise on disability, the results of this section are in line with those of Suo et al. [35], Khadem Al-sharia et al. [36], and Soltani et al. [37]. Soltani et al. examined the effect of a water training plan for 8 weeks on improving the physical disability in MS patients with EDSS and concluded that performing the selected aerobic exercises in the water can improve the physical disability of MS patients. Khadem Al-sharia et al. (2018) reported that 12 weeks of resistance and endurance training positively impacted physical disability in female MS patients. Suo et al. (2019) investigated the impact of a rehabilitation plan on neuromyelitis optica (an inflammatory disease that targets the optic nerves and spinal cord) and found out that physical disability of these patients was considerably improved.

The results were not consistent with those of Catalan et al. [38], and Tofighi et al. [3]. In the research by Catalan, $20 \mathrm{MS}$ patients with fatigue underwent neuro-cognitive rehabilitation training twice a week for five weeks. The patients were assessed using fatigue severity scale (FSS), modified fatigue impact scale (MFIS), multiple sclerosis quality of life-54, EDSS, and Multiple Sclerosis (MS) functional composite (MSFC). After treatment, FSS and MFIS showed a reduction in fatigue; however, there were no difference in the disability scale. These results can be attributed to the small sample size or difference in the disease type, which were merely relapsing-remitting in the present research. In the research by Catalan, the participants were selected from patients with relapsingremitting MS, secondary progressive MS, or primary progressive MS. A total of 24 training sessions were carried out in the present research, which were 10 sessions 
in Catalan's research. Besides, the type of the training was neuro-cognitive that was different from that of the present research.

Tofight et al. studied the impact of 12 endurance training sessions on balance, fatigue, and physical disability in women with MS [3]. They concluded that the execution of 12 sessions of progressive endurance training could increase balance and decrease fatigue in MS patients, but it has no impact on the physical ability of the patients. The possible reason might be the difference in the exercise type. In the research by Tofighi, endurance training was used for increasing the strength of the upper and lower trunk muscles. If the upper and lower limb muscles are strong and the center of the body is weak, then the trunk may not have sufficient stability to produce efficient movements of the upper and the lower limb [39]. Another possible cause can be the difference in the degree of disability of patients. Tofighi et al. used patients with a disability degree of 1 to 4 . The results supported that physical exercise has a great impact on the improvement of disability in higher levels. To improve disability in patients with a lower degree of disability, more intense training must be employed [40]. Both studies concluded that the most critical difference is the lack of transcranial current stimulation. However, several studies examined the remitting impact of several sessions of the cerebellum and cerebrum a-tDCS on the effects of postural training on stable and dynamic postural stability and balance in healthy adults and people with postural disorders [41-43].

Since no related literature was found regarding the impact of transcranial current stimulation on disability, it is suggested that the researchers investigate the relationship of tDCS on the physical disability scale in MS patients. In the present research, the motivation, nutrition, sleep, and rest status of the participants during the tests or training sessions were not controlled, and these factors can affect the results. Considering that balance in women and men can have a considerable difference in different age ranges, it is suggested to conduct a study regarding the gender difference. It is also recommended to clarify the mechanism of action of the cerebral tDCS, optimal stimulation parameters, and intermediary factors in future studies. Besides, to precisely study the changes in the brain function and functional balance of MS patients, neuroimaging techniques can be used in future studies.

\section{Conclusion}

In general, the results indicated that the cerebellar tDCS plus core stability training has a beneficial impact on the balance and function of the posture, and control sensory systems of MS patients. Besides, it can reduce the degree of disability in MS patients. Furthermore, the results demonstrated that the cerebellum, vestibular system, and visual system were interrelated and influenced the balance and that cerebral stimulation can facilitate learning motor skills.

\section{Ethical Considerations}

\section{Compliance with ethical guidelines}

This research was approved by the Ethics Committee of the Sports Science Report Institute and the Ethics Committee in Biomedical Research (Code: IR.SSRC. REC.1399.063).

\section{Funding}

This research did not receive any grant from funding agencies in the public, commercial, or non-profit sectors.

\section{Authors' contributions}

All authors equally contributed to preparing this article.

\section{Conflict of interest}

The authors declared no conflict of interest.

\section{Acknowledgments}

We would like to thank the authorities of Rofeideh Rehabilitation Hospital for their assistance in this study and all MS patients who participated in this study.

\section{References}

[1] Mirzaei M, Sahebozamani M, Ebrahimi H. [Comparing the effectiveness of selected tai chi exercises and core stabilization exercises on static and dynamic balance in multiple sclerosis patients with emphasis on edss: A clinical trial (Persian)]. Journal of Advances in Medical and Biomedical Research. 2017; 25(111):1-14. https://www.sid.ir/en/journal/ ViewPaper.aspx?ID=529907.

[2] Gutierrez GM, Chow JW, Tillman MD, McCoy SC, Castellano V, White LJ. Resistance training improves gait kinematics in persons with multiple sclerosis. Archives of Physical Medicine and Rehabilitation. 2005; 86(9):1824-9. [DOI:10.1016/j.apmr.2005.04.008] [PMID]

[3] Tofighi A, Saki Y, Razmjoo K. [Effect of 12-week progressive resistance training on balance, fatigue and disability in women with MS (Persian)]. Jundishapur Scientific Medical Journal. 2013; 12(2):159-67. https://jsmj.ajums.ac.ir/article_49344.html?lang=en 
[4] Trojano M, Paolicelli D, Tortorella C, Iaffaldano P, Lucchese G, Di Renzo V, et al. Natural history of multiple sclerosis: Have available therapies impacted long-term prognosis? Neurologic clinics. 2011; 29(2):309-21. [DOI:10.1016/j. ncl.2010.12.008] [PMID]

[5] Sari Aslany S, Azghani MR, Eftekharsadat B. [Effect of stability training on balance recovery in multiple sclerosis patients using sample entropy as a nonlinear analysis method (Persian)] Journal of Research in Rehabilitation Sciences. 2014; 10(3): 444-58 http://jrrs.mui.ac.ir/index.php/jrrs/article/view/1325/0

[6] Nilsagård Y, Lundholm C, Denison E, Gunnarsson LG. Predicting accidental falls in people with multiple sclerosis-a longitudinal study. Clinical Rehabilitation. 2009; 23(3):259-69. [DOI:10.1177\%2F0269215508095087] [PMID]

[7] Kasser SL, Jacobs JV, Foley JT, Cardinal BJ, Maddalozzo GF. A prospective evaluation of balance, gait, and strength to predict falling in women with multiple sclerosis. Archives of Physical Medicine and Rehabilitation. 2011; 92(11):1840-6. [DOI:10.1016/j.apmr.2011.06.004] [PMID]

[8] Daroff RB, Fenichel GM, Jankovic J, Mazziotta JC. Neurology in clinical practice. Amsterdam: Elsevier Health Sciences, 2012. https://www.google.com/books/edition/Neurology_in_Clinical_Practice/mpnaPQd_fZsC?hl=en\&gbpv $=0$

[9] Mazdeh M. [Comparing the efficacy of Avonex, Rebif and Betaferon in motor disability (Expanded Disability Status Scale) and relapsing rate of multiple sclerosis patients (Persian)]. Medical Sciences Journal. 2007; 17(3):139-46. http:// tmuj.iautmu.ac.ir/article-1-66-fa.html.

[10] Ebrahimi Atri A, Sokhangoi M, Sarvari F. [The comparison of resistance and endurance exercises on fatigue severity and balance in women with multiple sclerosis (Persian)] Journal of Exercise Science and Medicine. 2013; 5(1):89-102 [DOI:10.22089/smj.2017.3473.1190]

[11] Mohamadi Dinani Z, Nezakatolhossaini M, Esfarjani F, Etemadifar M. [The effect of eight-week Pilates training on motor function and depression in subjects with Multiple Sclerosis (MS) (Persian)]. Journal of Research in Rehabilitation Sciences. 2013; 9(2):308-17. http://jrrs.mui.ac.ir/index. $\mathrm{php} / \mathrm{jrrs} /$ article/view/669

[12] Shahrokhi H, Abbasi H, Mohammadi F, Rahmani P. [The effect of core stability exercises on endurance and trunk control in patients with multiple sclerosis (Persian)]. Sport Medicine Studies. 2017; 9(21):83-100. [DOI:10.22089/ smj.2017.3473.1190]

[13] Ghasemi E, Shayegannejad V, Ashtari F, Mordi B, Eraj R, Keivanfar N. [An investigation on the effects of neuromuscular exercise on balance, gait and the depression of paitent with MS (Persian)]. Journal of Research In Rehabilitation Sciences. 2011; 7(2):149-54. https://www.sid.ir/en/journal/ ViewPaper.aspx?id=255517

[14] Umphred D, Carlson C. Neurorehabilitation for the physical therapist assistant. New Jersey: Slack Incorporated; 2006. https://www.google.com/books/ edition/Neurorehabilitation_for_the_Physical_The/ xbFZXvK5VzEC?hl=en\&gbpv $=0$

[15] Mokhtari P, Tayebi Meybodi A. Neural basis of human movement. Tehran: Hatmi publication; 2019. https:/ / fidibo. com/book/107601-\%86
[16] Mousavi Sadati SK, Rashidzadeh P. [Effect of cerebellar transcranial direct current stimulation on balance and sensory system of the elderly (Persian)]. Scientific Journal of Rehabilitation Medicine. 2019; 8(4):195-205. [DOI:10.22089/ smj.2017.3473.1190]

[17] Yahia M, Al-Harbi TM, Bashir S. The potential rehabilitation role of transcranial Direct Current Stimulation (tDCS) in multiple sclerosis. Neurology, Psychiatry and Brain Research. 2018; 30:9-11. [DOI:10.1016/j.npbr.2018.04.003]

[18] de Moura MCDS, Hazime FA, Marotti Aparicio LV, Grecco LAC, Brunoni AR, Hasue RH. Effects of transcranial Direct Current Stimulation (tDCS) on balance improvement: A systematic review and meta-analysis. Somatosensory \& Motor research. 2019; 36(2):122-35. [DOI:10.1080/08990220.2019.16 24517] [PMID]

[19] Brunoni AR, Nitsche MA, Bolognini N, Bikson M, Wagner $\mathrm{T}$, Merabet L, et al. Clinical research with transcranial Direct Current Stimulation (tDCS): Challenges and future directions. Brain Stimulation. 2012; 5(3):175-95. [DOI:10.1016/j. brs.2011.03.002] [PMID] [PMCID]

[20] Shahrjerdi S, Golpayegani M, Faraji F, Masoumi M. [Effect of eight weeks Yoga and core stabilization exercises on balance in women with multiple sclerosis (Persian)]. Razi Journal of Medical Sciences (Journal of Iran University of Medical Sciences). 2016; 22(140):32-42. https://www.sid.ir/en/ journal/ViewPaper.aspx?ID=508610

[21] Folstein MF, Folstein SE, McHugh PR. “Mini-mental state": A practical method for grading the cognitive state of patients for the clinician. Journal of Psychiatric Research. 1975; 12(3):189-98. [DOI:10.1016/0022-3956(75)90026-6]

[22] Birmingham University. tDCS and TACS Safety Questionnaire. Birmingham: Birmingham University; 2015 http:/ / prism.bham.ac.uk/downloads/TDCS_Safety_Qs_ConsentForm_30092015.pdf.

[23] Kurtzke JF. Rating neurologic impairment in multiple sclerosis: An Expanded Disability Status Scale (EDSS). Neurology. 1983; 33(11):1444-52. [DOI:10.1212/WNL.33.11.1444] [PMID]

[24] Seyedian M, Falah M, Nourouzian M, Nejat S, Delavar A, Ghasemzadeh HA. [Validity of the Farsi Version of MiniMental State Examination (Persian)]. Journal of Medical Council of I.R.I. 2008; 25(4):408-14. https:/ / www.sid.ir/en/ journal/ViewPaper.aspx?ID=133666

[25] Hebert JR, Manago MM. Reliability and validity of the computerized dynamic posturography sensory organization test in people with Multiple Sclerosis. International Journal of MS Care. 2017; 19(3):151-7. [DOI:10.7224/1537-2073.2016027] [PMID] [PMCID]

[26] Whitney SL, Roche JL, Marchetti GF, Lin CC, Steed DP, Furman GR, et al. A comparison of accelerometry and center of pressure measures during computerized dynamic posturography: A measure of balance. Gait \& Posture. 2011;33(4):594-9. [DOI:10.1016/j.gaitpost.2011.01.015] [PMID] [PMCID]

[27] Yosephi MH, Ehsani F, Zoghi M, Jaberzadeh S. Multi-session anodal $\mathrm{tDCS}$ enhances the effects of postural training on balance and postural stability in older adults with high fall risk: Primary motor cortex versus cerebellar stimulation. Brain Stimulation. 2018; 11(6):1239-50. [DOI:10.1016/j. brs.2018.07.044] [PMID] 
[28] Pilloni G, Choi C, Shaw M, Sherman K, Pau M, Krupp L, et al. transcranial Direct Current Stimulation (tDCS) can enhance physical training outcomes in Multiple Sclerosis (MS) (P3. 2-029). Neurology. 2019; 92(15 Suppl):P3.2-029. https://n. neurology.org/content/92/15_Supplement/P3.2-029

[29] Pilloni G, Choi C, Coghe G, Cocco E, Krupp LB, Pau M, et al. Gait and functional mobility in multiple sclerosis: Immediate effects of transcranial Direct Current Stimulation (tDCS) paired wth Aerobic exercise. Frontiers in Neurology. 2020; 11:310. [DOI:10.3389/fneur.2020.00310] [PMID] [PMCID]

[30] Edwards WH. Motor learning and control: From theory to practice. Boston: Cengage Learning; 2010. https://www. google.com/books/edition/Motor_Learning_and_Control_From_Theory_t/qeYHAAAAQBAJ?hl=en\&gbpv $=0$.

[31] Park IS, Lee NJ, Rhyu IJ. Roles of the declive, folium, and tuber cerebellar vermian lobules in sportspeople. Journal of Clinical Neurology. 2018; 14(1):1-7. [DOI:10.3988/ jcn.2018.14.1.1] [PMID] [PMCID]

[32] Zandvliet SB, Meskers CGM, Kwakkel G, van Wegen EEH. Short-term effects of cerebellar tDCS on standing balance performance in patients with chronic stroke and healthy age-matched elderly. The Cerebellum. 2018; 17(5):575-89. [DOI:10.1007/s12311-018-0939-0] [PMID] [PMCID]

[33] Poortvliet P, Hsieh B, Cresswell A, Au J, Meinzer M. Cerebellar transcranial direct current stimulation improves adaptive postural control. Clinical Neurophysiology. 2018; 129(1):33-41. [DOI:10.1016/j.clinph.2017.09.118] [PMID]

[34] Steiner KM, Enders A, Thier W, Batsikadze G, Ludolph N, Ilg W, et al. Cerebellar tDCS does not improve learning in a complex whole body dynamic balance task in young healthy subjects. PloS One. 2016; 11(9):e0163598. [DOI:10.1371/journal.pone.0163598] [PMID] [PMCID]

[35] Suo DM, Liu LL, Jia K, Zhang LJ, Li LM, Wang J, et al. Multidisciplinary rehabilitation for adults with neuromyelitis optica spectrum disorders: A pilot study. Journal of Rehabilitation Medicine. 2019; 51(9):692-7. [DOI:10.2340/165019772587] [PMID]

[36] Khademosharie M, Tadibi V, Behpor N, Hamedinia M. [Effect of 12-week endurance-resistance training on motor and muscular function, degree of disability, fatigue, and quality of life in Multiple Sclerosis patients (Persian)]. Iranian Journal of Epidemiology. 2018; 14(1):95-104. http://irje.tums. ac.ir/article-1-5968-en.html

[37] Soltani M, Hejazi Sm, Noorian A, Zendedel A, Ashkanifar F. [The effect of aerobic training on the improvement of expanded disability status scale (edss) in multiple sclerosis patients (Persian)]. Journal of Medical Science of Islamic Azad University of Mashhad. 2009; 5(17):15-20. https://www.sid. ir/en/journal/ViewPaper.aspx?ID=204704.

[38] Catalan M, De Michiel A, Bratina A, Mezzarobba S, Pellegrini $\mathrm{L}$, Marcovich R, et al. Treatment of fatigue in multiple sclerosis patients: A neurocognitive approach. Rehabilitation Research and Practice. 2011; 2011:670537. [DOI:10.1155/2011/670537] [PMID] [PMCID]

[39] Prentice WE. Rehabilitation techniques for sports medicine and athletic training. Thorofare, NJ: SLACK Incorporated; 2015. https://www.google.com/books/edition/Rehabilitation_Techniques_for_Sports_Med/pvAyngEACAAJ?hl=en
[40] Amiri B, Sahebozamani M, Sedighi B. The effects of 10-week core stability training on balance in women with multiple sclerosis according to Expanded Disability Status Scale: A single-blinded randomized controlled trial. European Journal of Physical and Rehabilitation Medicine. 2019; 55(2):199-208. [DOI:10.23736/S1973-9087.18.04778-0] [PMID]

[41] Duarte Nde A, Grecco LA, Galli M, Fregni F, Oliveira CS. Effect of transcranial direct-current stimulation combined with treadmill training on balance and functional performance in children with cerebral palsy: A double-blind randomized controlled trial. PloS One. 2014; 9(8):e105777. [DOI:10.1371/ journal.pone.0105777] [PMID] [PMCID]

[42] Ehsani F, Samaei A, Zoghi M, Hedayati R, Jaberzadeh S. The effects of cerebellar transcranial direct current stimulation on static and dynamic postural stability in older individuals: a randomized double-blind sham-controlled study. European Journal of Neuroscience. 2017; 46(12):2875-84. [DOI:10.1111/ejn.13731] [PMID]

[43] Grecco LA, Oliveira CS, Duarte NA, Lima VL, Zanon N, Fregni F. Cerebellar transcranial direct current stimulation in children with ataxic cerebral palsy: A sham-controlled, crossover, pilot study. Developmental Neurorehabilitation. 2017 20(3):142-8. [DOI:10.3109/17518423.2016.1139639] [PMID] 
This Page Intentionally Left Blank 